\title{
The crystal-induced activation of NLRP3 inflammasomes in atherosclerosis
}

\author{
Tadayoshi Karasawa* and Masafumi Takahashi
}

\begin{abstract}
Atherosclerosis is an inflammatory disease, which is accompanied by the deposition of cholesterol-rich lipids and the infiltration of macrophages. Other well-known features of atherosclerotic lesions include the deposition of cholesterol crystals and calcium phosphate crystals; however, their pathophysiological role remains unclear. Recent studies suggest that cholesterol crystals play a pivotal role in activation of NLRP3 inflammasomes, which regulate caspase- 1 activation and the subsequent processing of IL-1 $\beta$, in atherosclerotic lesions. NLRP3 inflammasomes are essential for the initiation of vascular inflammation during the progression of atherosclerosis. Therefore, the regulatory mechanisms of NLRP3 inflammasomes are regarded as potential targets for atherosclerosis treatment. Here, we review the current knowledge regarding the role of NLRP3 inflammasomes in the progression of atherosclerosis and the prospects for therapeutic approaches targeting NLRP3 inflammasomes.
\end{abstract}

Keywords: Cholesterol, Cytokines, Inflammation, Interleukin-1, Macrophages

\section{Background}

Atherosclerosis is an inflammatory disease characterized by the deposition of cholesterol-rich lipids and the macrophage infiltration of the vascular walls [1]. Infiltrated macrophages uptake cholesterol and cause inflammatory responses by producing various cytokines and chemokines. The mechanism of cholesterol accumulation in atherosclerotic lesions has been well described. For example, infiltrated macrophages incorporate modified low-density lipoprotein (LDL) via scavenger receptors and accumulate in the atherosclerotic lesions as lipid-loaded foam cells [2]. However, the molecular mechanisms by which lipids induce inflammatory responses are not been fully understood. In particular, the deposition of cholesterol crystals is a well-known feature of atherosclerosis [3], although the precise role of cholesterol crystals in the pathophysiology of atherosclerosis remains unclear. Recently, the molecular complexes called nucleotidebinding oligomerization domain-like receptor (NLR) family, pyrin domain containing 3 (NLRP3) inflammasomes have emerged as a key player for the crystalinduced inflammation in atherosclerosis $[4,5]$.

\footnotetext{
* Correspondence: tdys.karasawa@jichi.ac.jp

Division of Inflammation Research, Center for Molecular Medicine, Jichi Medical University, 3311-1 Yakushiji, Shimotsuke, Tochigi 329-0498, Japan
}

NLRP3 is a pattern recognition receptor (PRR), which participates in innate immune responses by recognizing danger signals, including pathogen-associated molecular patterns (PAMPs) and damage/danger-associated molecular patterns (DAMPs) [6]. The PRRs are evolutionarily conserved and expressed in the cells involved in the innate immune system such as macrophages, neutrophils, and dendritic cells [7]. The PRRs are classified into several groups according to their conserved structure and function. For instance, toll-like receptors (TLR) and C-type lectin receptors (CLRs) are expressed on the membrane surface, while NLRs and retinoic acid-inducible gene-Ilike receptors (RLRs) exhibit intracellular localization. Recently, the involvement of several PRRs in the progression of atherosclerosis has been unveiled. Among PRRs, TLR 2 and TLR4 are activated by inflammatory lipids, such as oxidized LDL and saturated fatty acids $[1,2]$. Furthermore, NLRP3 is involved in the cholesterol crystalmediated inflammatory response through the assembly of molecular complexes called inflammasomes. NLRP3 inflammasomes regulate inflammatory responses via processing of interleukin (IL)-1 $\beta$, which is a potent inflammatory cytokine. Indeed, previous reports suggest that the development of atherosclerosis development was attenuated in the absence of NLRP3 inflammasomes [4, 8-10]. In this review, we describe the molecular mechanisms of 
crystal-mediated NLRP3 inflammasome activation and the regulatory mechanisms of NLRP3 inflammasomes in the atherosclerotic lesions.

\section{What is the inflammasome?}

Inflammasomes are multiple cytoplasmic protein complexes, which are typically composed of NLRs, apoptosisassociated speck-like protein containing a caspase recruitment domain (CARD) (ASC), and caspase-1 (Fig. 1). In response to DAMPs or PAMPs, components of inflammasomes assemble through the interaction of pyrin domain (PYD) and caspase recruitment domain (CARD) [11]. Assembled inflammasomes form large molecular complexes and serve as a molecular platform for caspase- 1 activation. Caspase- 1 is a cysteine protease, which was originally identified as an interleukin-1 converting enzyme [12]. Therefore, inflammasome-mediated activation of caspase- 1 converts inactive pro-IL- $1 \beta$ to its mature form. Among NLRs, at least NLRP1, NLRP3, NLRC4, NLRP6, and NLRP12 participate in inflammasomes as core components of the complexes [11]. Besides NLRs, PYHIN (pyrin and HIN domain-containing protein) family proteins, including absence in melanoma 2 (AIM2) and IFN-g-inducible protein 16 (IFI16), are also known as core components of inflammasomes. The adaptor protein ASC is necessary for several core components, such as NLRP3 and AIM2, for inflammasome assembly, while NLRC4 can assemble without ASC. Inflammasomes are named according to their core components. For example, the complexes composed of NLRP3, ASC, and caspase-1 are called NLRP3 inflammasomes. The core components of inflammasomes are activated by different danger signals. NLRC4 inflammasomes are activated by flagellin, a protein derived from flagellum of bacteria [13], while NLRP1 also recognizes, a lethal toxin derived from bacteria [14]. AIM2 functions as a sensor molecule for viral infection by recognizing cytosolic double-strand DNA [15]. NLRP3 is distinct from other core components because NLRP3 is activated by both DAMPs and PAMPs, while other core components are mainly activated by PAMPs and are involved in infection [6].

\section{NLRP3 inflammasomes}

NLRP3 inflammasomes are activated by DAMPs as well as PAMPs and thus involved in both sterile inflammation and host defense [6]. DAMPs, including extracellular adenosine triphosphate (ATP) and monosodium urate (MSU) crystals, induce the assembly of NLRP3 inflammasomes to activate caspase-1 (Fig. 1). The interaction among components of NLRP3 inflammasomes is mediated by conserved domains, which exhibit homophilic interaction. NLRP3 contains three domains: C-terminal leucine-rich repeats (LRRs), a central nucleotide domain termed the NACHT domain, and an N-terminal PYD. ASC can function as an adaptor molecule because it is composed of an N-terminal PYD and a C-terminal CARD. Caspase- 1 also has a CARD and catalytic domains (p10 and p20). When cells are exposed to danger signals, NLRP3 assembles homotypically by the NACHT domain and offers scaffold for filamentous assembly of ASC by their interaction of PYD [16]. Subsequently, the assembled ASC promotes recruitment of caspase-1 via CARD-CARD interaction and subsequent auto-activation of caspase-1.

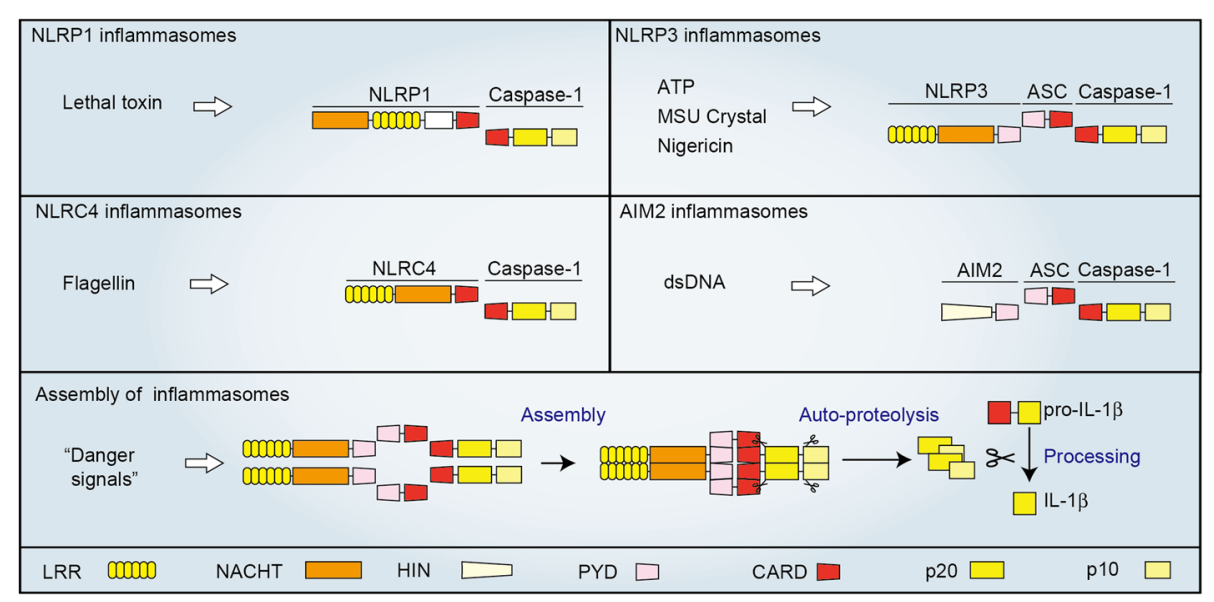

Fig. 1 Components of inflammasomes. Several PRRs, which recognize distinct DAMPs, form the inflammasome complex that serves as a molecular platform for caspase-1 activation. NLRP1 inflammasomes are composed of NLRP1 and caspase-1 and are activated by lethal toxins. The components of NLRP3 inflammasomes are NLRP3, ASC, and caspase-1. NLRP3 binds ASC via PYD-PYD interaction. ASC subsequently binds caspase-1 via CARD-CARD interaction. NLRP3 inflammasomes are activated by both PAMPs and DAMPs, such as adenosine triphosphae (ATP), nigericin, and monosodium urate (MSU) crystals. NLRC4 inflammasomes are composed of NLRC4 and caspase-1 and are activated by flagellin. AIM2 inflammasomes are composed of AIM2, ASC, and caspase-1 and recognize double-strand DNA (dsDNA) 
The activated caspase- 1 exerts proinflammatory effects by its proteolytic activity. Besides IL-1 $\beta$, caspase1 converts pro-IL-18 to its bioactive mature form. Furthermore, caspase-1 also cleaves gasdermin D (GSDMD) to induce pyroptosis, an inflammatory programed cell death accompanied by an increased permeability of the plasma membrane $[17,18]$. Because IL- $1 \beta$ has no signal sequence for exocytosis, pyroptosis-mediated membrane permeabilization seems to be necessary for IL-1 $\beta$ release $[19,20]$.

The release of IL-1 $\beta$ is induced by a two-step regulation: transcriptional regulation called the priming step and processing by inflammasomes (Fig. 2). The transcriptional regulation of $I l 1 b$ (signal 1) is mediated by PRRs or cytokine receptors including TLRs and IL-1 receptors (IL-1R). Besides NF-kB-mediated mRNA induction of $I l 1 b$ and Nlrp3, activation of these receptors primes NLRP3 by posttranscriptional regulation, such as ubiquitination and deubiquitination [21, 22]. Then, accumulated cytosolic pro-IL-1 $\beta$ in cytosol is rapidly processed by caspase- 1 , which is activated by NLRP3 inflammasomes (signal 2). Since IL-1 $\beta$ exhibits potent proinflammatory effects, this two-step regulation is thought to be necessary for maintenance of immuno-homeostasis.

Although various endogenous or exogenous danger signals such as ATP, MSU crystals, and silica are known to activate NLRP3 inflammasomes, the precise mechanism by which NLRP3 recognizes the danger signals remains unclear [23, 24]. Unlike other PRRs, the direct ligands of NLRP3 are almost unknown and still controversial. Only a few reports suggest that mitochondrial DNA or mitochondria-derived cardiolipin functions as a direct ligand of NLRP3. Conversely, upstream molecular machineries of NLRP3 inflammasomes have been elucidated. Several common pathways including potassium $\left(\mathrm{K}^{+}\right)$efflux, generation of mitochondrial reactive oxygen species (ROS), and lysosomal destabilization are necessary for the activation of the NLRP3 inflammasome [6]. In particular, lysosomal destabilization and subsequent cathepsin B release is a common pathway for NLRP3 inflammasome activation by crystals and particulate matter. Thus, the regulatory mechanisms of NLRP3 inflammasomes have not been completely elucidated.

\section{NLRP3 inflammasomes in the pathogenesis of diseases}

Originally, NLRP3 was identified as a responsible gene for cryopyrin-associated periodic syndrome (CAPS), which includes three syndromes with differing severity [25]. Familial cold autoinflammatory syndrome (FCAS) is the mildest condition and is characterized by cold-induced fever and inflammation. Muckle-Wells syndrome (MWS) is a moderate condition and is characterized by episodic attacks with fever and urticaria-like rash. MWS patients also exhibit arthralgia and progressive hearing loss. Chronic infantile neurological cutaneous and articular

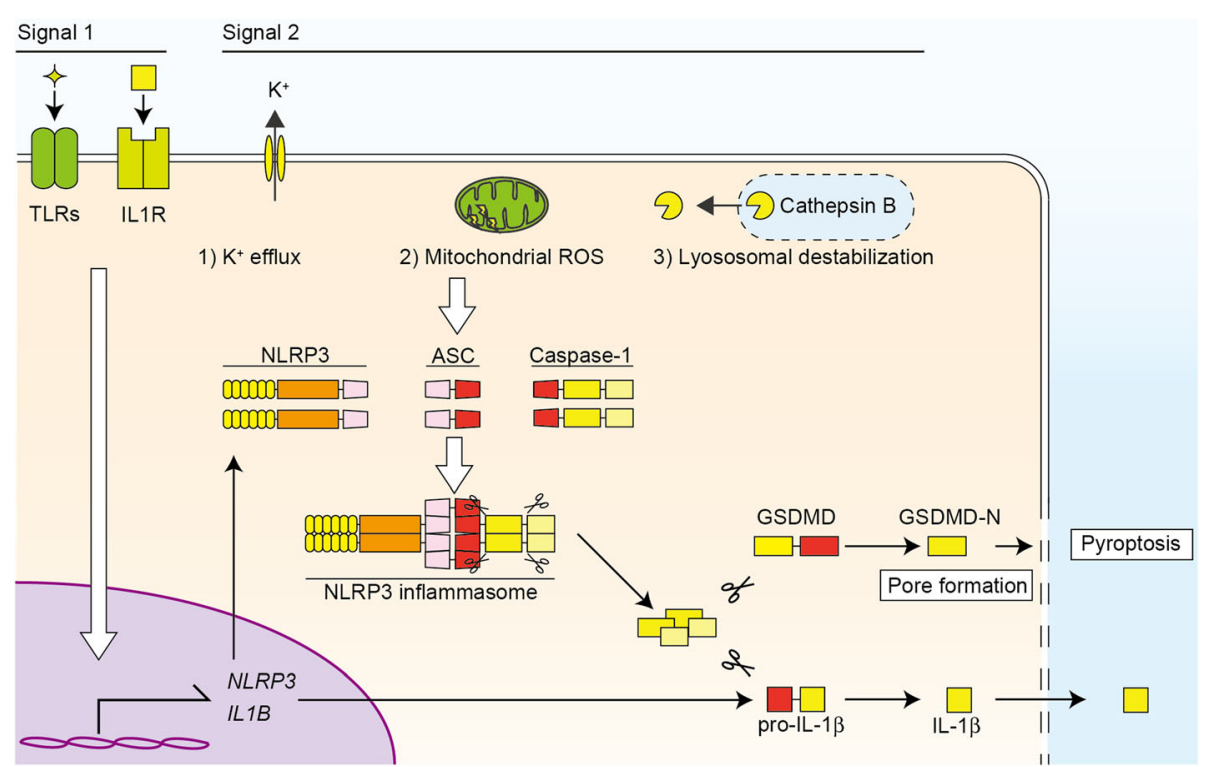

Fig. 2 Mechanisms of NLRP3 inflammasome-driven IL-1 $\beta$ release. IL-1 $\beta$ release is regulated by a two-step regulation: transcriptional synthesis of pro-IL-1 $\beta$ and proteolytic processing into its mature form by the inflammasomes. The transcriptional regulation of IL-1 $\beta$ mRNA is mediated by TLRs and IL-1 receptor (signal 1), which also induces NLRP3 mRNA expression. Then, NLRP3 inflammasomes induce caspase-1 activation and the subsequent conversion of pro-IL-1 $\beta$ to its mature form (signal 2). As common upstream pathways of NLRP3 inflammasomes, three mechanisms are known: (1) potassium efflux, (2) generation of mitochondrial ROS, and (3) lysosomal destabilization and leakage of cathepsin B. Activated caspase-1 also cleaves GSDMD, whose processed N-terminal fragment (GSDMD-N) forms plasma membrane pores to increase membrane permeability, resulting in pyroptosis 
syndrome (CINCA) is the most severe condition with continuous inflammation, which results in neurological impairment. Since CAPS is a rare genetic disease, few investigations of NLRP3 inflammasomes had been performed until the link between NLRP3 inflammasomes and sterile inflammation was uncovered. However, the discovery that the NLRP3 inflammasome is activated by MSU crystals and associated with gout highlights the role of NLRP3 inflammasomes in sterile inflammatory diseases [23]. Indeed, we and others have revealed a pivotal role of NLRP3 inflammasomes in the development of cardiovascular and renal diseases including atherosclerosis [4, 8, 26-29]. Furthermore, in the last decade, numerous studies revealed that NLRP3 inflammasomes are activated by a broad variety of danger signals and are involved in various inflammatory diseases [6].

\section{Crystal-induced NLRP3 inflammasome activation}

Among danger signals that activate NLRP3 inflammasomes, crystals and particulate matter share similar molecular mechanisms to activate NLRP3 inflammasomes. Innate immune cells, including macrophages and neutrophils, engulf these particles to remove foreign substances. However, excess loads of particles in lysosome cause an indigestion called "frustrated lysosome," which in turn induces lysosome destabilization. As described above, the leakage of cathepsin $\mathrm{B}$ into the cytosol triggers NLRP3 inflammasome activation. Although downstream mechanisms of cathepsin B release are still unclear, $\mathrm{K}^{+}$efflux is regarded as essential for the activation of NLRP3 inflammasomes induced by lysosomal destabilization [30, 31].

NLRP3 inflammasome activation induced by crystals and particles is associated with various inflammatory diseases (Fig. 3). As endogenous crystals, MSU crystals and calcium pyrophosphate dehydrate (CPPD) crystals are known to activate the NLRP3 inflammasome and cause inflammation in gout and pseudo-gout, respectively [23]. Exogenous particles such as silica and asbestos are associated with inflammation in silicosis and asbestos lung [32, 33]. However, factors that induce lysosomal destabilization are not limited to crystals and particulate matter. Some kinds of protein aggregates also activate NLRP3 inflammasomes. $\beta$-amyloid associated with Alzheimer's disease is capable of activating NLRP3 inflammasomes [34]. Furthermore, NLRP3 inflammasome complex in the extracellular space can function as a danger signal of NLRP3 inflammasomes itself. The assembly of NLRP3 inflammasome components causes the formation of aggregates called speck, which are released to the extracellular space after NLRP3 inflammasome activation $[35,36]$. The released NLRP3 inflammasomes are incorporated into neighbor cells in which they activate NLRP3 inflammasomes in part by lysosomal destabilization. Thus,

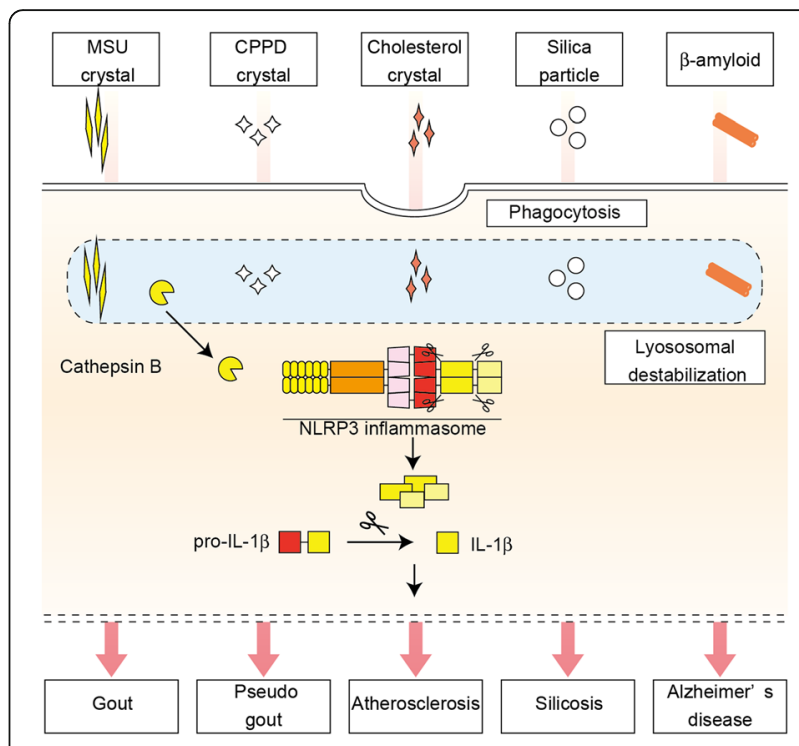

Fig. 3 NLRP3 inflammasome activation mediated by lysosomal destabilization. Various endogenous crystals and exogenous particulate matter activate NLRP3 inflammasomes and cause inflammatory diseases. Phagocytosed particles cause lysosomal destabilization and rupture, which induce the leakage of lysosomal enzyme cathepsin B, resulting in the activation of NLRP3 inflammasomes. As a factor that induces lysosome destabilization, the following crystals or particles are known: MSU crystals, calcium pyrophosphate (CPPD) crystals, cholesterol crystals, silica particles, and $\beta$-amyloid

various kinds of particles including crystals activate NLRP3 inflammasomes and initiate inflammatory responses.

\section{NLRP3 inflammasomes in atherosclerosis}

In the advanced atherosclerotic lesion, the deposition of cholesterol crystals and calcium phosphate crystals are reported [3]. However, their pathophysiological relevance to atherosclerosis development remained unclear. In 2010, Douwell et al. [4] revealed that cholesterol crystals are deposited even in the early stage of atherosclerotic lesion and activate NLRP3 inflammasomes via lysosomal destabilization. Interestingly, they further showed that oxidized LDL, a major lipid species in atherosclerotic lesions, not only induces cholesterol crystallization but also provides priming signals to induce NLRP3 and pro-IL-1 $\beta$ expression. Thus, it is suggested that oxidized LDL could be sufficient to provide signals 1 and 2 to induce IL-1 $\beta$ release. According to a subsequent report by Sheedy et al. [37], incorporation of oxidized LDL via scavenger receptor CD36 provokes intracellular crystallization of cholesterol. On the other hand, calcium phosphate is also particulate matter, which is accumulated in atherosclerotic lesions and associated with vascular calcification. In this regard, we and other investigators showed that calcium phosphate crystals, including hydroxyl apatite and tricalcium 
phosphate, activate NLRP3 inflammasomes through lysosomal rupture and subsequent cathepsin B release [8].

Since several studies have shown that IL- $1 \beta$ contributes to the progression of atherosclerosis [38, 39], it is expected that the deficiency of NLRP3 inflammasomes prevents atherosclerosis. Indeed, recent studies reported that the deficiency of NLRP3 inflammasome components prevents the atherosclerosis progression $[4,8-10]$. However, Menu et al. [40] reported that deficiency of NLRP3 inflammasomes failed to prevent the development of atherosclerosis in $\mathrm{ApoE}^{-/-}$mice. The reason for this discrepancy is unclear, but the highly atherogenic diet used in the study by Menu et al., in comparison with other studies, may have influenced the immune status and inflammatory responses.

\section{The regulatory mechanisms of NLRP3 inflammasomes}

The regulatory mechanisms of NLRP3 inflammasomes may be a potential target for multiple inflammatory diseases including atherosclerosis. The possible mechanisms are the following: (1) modification of the inflammasome components including phosphorylation and ubiquitination, (2) modulation of the NLRP3 inflammasome assembly, (3) the upstream pathways of NLRP3 inflammasome activation, and (4) the destruction of NLRP3 inflammasome complexes. Among NLRP3 inflammasome components, the modification of NLRP3 is critical for inflammasome assembly. The priming signal provided by TLR or IL-1R promotes deubiquitination of NLRP3, which licenses the assembly of NLRP3 inflammasomes [41]. To date, BRCC3 has emerged as the only enzyme that can deubuiquitinate NLRP3 [22], while several E3 ubiquitine ligases such as FBXL12, MARCH7, and TRIM31 are reported to ubiquitinate NLRP3 [42-44]. Further reports suggest that protein kinase A directly inhibits NLRP3 via phosphorylation at Ser 291 and promotes the subsequent ubiquitination [45].

Since oligomerization of NLRP3 inflammasome components is a critical step for inflammasome activation, proteins which interact with the components can modify the assembly of NLRP3 inflammasomes. As a positive regulator of NLRP3 inflammasomes, NEK7 was found to participate in NLRP3 inflammasome complexes [46-48]. Additionally, negative regulatory proteins that prevent assembly of the NLRP3 inflammasomes by direct interaction with components are also reported. For example, CARD-only proteins (COPs) and PYD-only proteins (POPs) are typical molecules that modify NLRP3 inflammasome assembly [49]. These proteins are homologues of caspase- 1 and ASC and consist of only CARD or PYD. Among these proteins, POP1 inhibits NLRP3 inflammasome activation by the prevention of ASC oligomerization [50]. Although all the COPs and POPs were first reported as negative regulators of caspase-1 activation [51-53], the roles of COPs and POPs in NLRP3 inflammasome activation remain controversial. In this regard, we previously found that CARD16 induces caspase- 1 activation by promoting filamentous assembly of caspase-1 [54]. Furthermore, $\beta$-arrestin-2, which functions as a downstream scaffold protein of $\mathrm{G}$ protein-coupled receptor 120 (GPR120), is suggested to be a potential negative regulator of NLRP3 inflammasome assembly. Yan et al. reported that the activation of GPR120 by polyunsaturated fatty acids inhibits NLRP3 inflammasomes via the direct interaction between $\beta$ arrestin-2 and NLRP3 [55].

The upstream pathways for NLRP3 inflammasome activation are also potential targets. Since mitochondriaderived ROS plays essential roles in the activation of NLRP3 inflammasomes, clearance of damaged mitochondria by autophagy (mitophagy) can inhibit the activation of NLRP3 inflammasomes [56]. Indeed, accelerated atherosclerotic lesion with enhanced NLRP3 inflammasome activation was observed in autophagydefective Atg5-deficient mice [57]. Furthermore, lysosome biogenesis may protect against crystal-induced NLRP3 inflammasome activation. Activation of lysosome biogenesis by overexpression of TFEB, which regulates lysosome and autophagy-related genes, inhibits NLRP3 inflammasome activation induced by cholesterol crystals and attenuates the progression of atherosclerosis [58]. However, the regulatory mechanism for the destruction of NLRP3 inflammasomes is largely unknown. Although it is suggested that autophagy promotes destruction of the NLRP3 inflammasome complex in a ubiquitin-dependent manner [59], the regulatory mechanism to ubiquitinate the inflammasome complex is undetermined. Thus, the regulatory mechanisms of the NLRP3 inflammasomes are not fully elucidated. Further studies are necessary for the NLRP3 inflammasomes to be therapeutic targets in inflammatory diseases.

\section{Conclusion}

Accumulating evidence suggests that NLRP3 inflammasomes play an essential role in the progression of inflammatory diseases. Lysosome-destabilizing particles, including crystals and particulate matter, are common molecules that trigger activation of the NLRP3 inflammasomes in various diseases. In the progression of atherosclerosis, cholesterol crystals or calcium phosphate crystals are involved in NLRP3 inflammasome-mediated inflammatory responses. Further study clarifying the molecular mechanisms of NLRP3 inflammasome activation would serve to develop a novel therapeutic approach to atherosclerosis and other inflammatory diseases, which are caused by crystals and particulate matter. 


\section{Abbreviation}

AIM2: Absence in melanoma 2; ASC: Apoptosis-associated speck-like protein containing a caspase recruitment domain; CAPS: Cryopyrin-associated periodic syndrome; CARD: Caspase recruitment domain; CINCA: Chronic infantile neurological cutaneous and articular syndrome; CLR: C-type lectin receptors; COPs: CARD-only proteins; CPPD: Calcium pyrophosphate dehydrate; DAMPs: Damage/danger-associated molecular patterns; FCAS: Familial cold autoinflammatory syndrome; GPR: G protein-coupled receptor; GSDMD: Gasdermin D; IFI16: IFN-g-inducible protein 16; IL: Interleukin LDL: Low-density lipoprotein; LRR: Leucine-rich repeats; MSU: Monosodium urate; MWS: Muckle-Wells syndrome; NLR: Nucleotide-binding oligomerization domain-like receptor; NLRP3: NLR family, pyrin domain containing 3; PAMPs: Pathogen-associated molecular patterns; POPs: PYD-only proteins; PRR: Pattern recognition receptor; PYD: Pyrin domain; RLR: Retinoic acid-inducible gene-I-like receptors; ROS: Reactive oxygen species; TLR: Toll-like receptors

\section{Acknowledgements}

We are grateful to our colleagues, laboratory member, and collaborators for their helpful suggestions and experimental assistance.

\section{Funding}

TK is supported by "Grant-in-Aid for Young Scientists (B)" from Japan Society for the Promotion of Science, Japan Heart Foundation \& Astellas Grant for Research on Atherosclerosis Update, and SENSIN Medical Research Foundation.

\section{Availability of data and materials}

Not applicable.

\section{Authors' contributions}

TK wrote the manuscript. MT critically revised the manuscript. Both authors read and approved the final manuscript.

\section{Ethics approval and consent to participate}

Not applicable.

\section{Consent for publication}

Not applicable.

\section{Competing interests}

The authors declare that they have no competing interests.

\section{Publisher's Note}

Springer Nature remains neutral with regard to jurisdictional claims in published maps and institutional affiliations.

\section{Received: 19 April 2017 Accepted: 13 July 2017}

\section{Published online: 11 September 2017}

\section{Reference}

1. Tall AR, Yvan-Charvet L. Cholesterol, inflammation and innate immunity. Nat Rev Immunol. 2015:15:104-16.

2. Moore KJ, Tabas I. Macrophages in the pathogenesis of atherosclerosis. Cell. 2011;145:341-55.

3. Small D. M. George Lyman Duff memorial lecture. Progression and regression of atherosclerotic lesions. Insights from lipid physical biochemistry. Arteriosclerosis. 1988;8:103-29.

4. Duewell P, Kono H, Rayner KJ, Sirois CM, Vladimer G, Bauernfeind FG, Abela GS, Franchi L, Nunez G, Schnurr M, Espevik T, Lien E, Fitzgerald KA, Rock KL, Moore KJ, Wright SD, Hornung V, Latz E. NLRP3 inflammasomes are required for atherogenesis and activated by cholesterol crystals. Nature. 2010:464:1357-61.

5. Rajamaki K, Lappalainen J, Oorni K, Valimaki E, Matikainen S, Kovanen PT, Eklund KK. Cholesterol crystals activate the NLRP3 inflammasome in human macrophages: a novel link between cholesterol metabolism and inflammation. PLoS One. 2010;5:e11765.

6. Guo H, Callaway JB, Ting JP. Inflammasomes: mechanism of action, role in disease, and therapeutics. Nat Med. 2015;21:677-87.

7. Takeuchi O, Akira S. Pattern recognition receptors and inflammation. Cell. 2010;140:805-20.
8. Usui F, Shirasuna K, Kimura H, Tatsumi K, Kawashima A, Karasawa T, Hida S, Sagara J, Taniquchi S, Takahashi M. Critical role of caspase-1 in vascular inflammation and development of atherosclerosis in Western diet-fed apolipoprotein E-deficient mice. Biochem Biophys Res Commun. 2012;425: 162-8.

9. Gage J, Hasu M, Thabet M, Whitman SC. Caspase-1 deficiency decreases atherosclerosis in apolipoprotein E-null mice. Can J Cardiol. 2012;28:222-9.

10. Hendrikx T, Jeurissen ML, van Gorp PJ, Gijbels MJ, Walenbergh SM, Houben T, van Gorp R, Pottgens CC, Stienstra R, Netea MG, Hofker MH, Donners MM Shiri-Sverdlov R. Bone marrow-specific caspase-1/11 deficiency inhibits atherosclerosis development in Ldlr-1/ mice. FEBS J. 2015;282:2327-38.

11. Lamkanfi M, Dixit VM. Mechanisms and functions of inflammasomes. Cell. 2014:157:1013-22.

12. Black RA, Kronheim SR, Merriam JE, March CJ, Hopp TP. A pre-aspartatespecific protease from human leukocytes that cleaves pro-interleukin-1 $\beta$. J Biol Chem. 1989;264:5323-6.

13. Franchi L, Amer A, Body-Malapel M, Kanneganti TD, Ozoren N, Jagirdar R, Inohara N, Vandenabeele P, Bertin J, Coyle A, Grant EP, Nunez G. Cytosolic flagellin requires Ipaf for activation of caspase- 1 and interleukin $1 \beta$ in salmonella-infected macrophages. Nat Immunol. 2006;7:576-82.

14. Levin TC, Wickliffe KE, Leppla SH, Moayeri M. Heat shock inhibits caspase-1 activity while also preventing its inflammasome-mediated activation by anthrax lethal toxin. Cell Microbiol. 2008;10:2434-46.

15. Fernandes-Alnemri T, Yu JW, Datta P, Wu J, Alnemri ES. AlM2 activates the inflammasome and cell death in response to cytoplasmic DNA. Nature. 2009:458:509-13.

16. Lu A, Magupalli VG, Ruan J, Yin Q, Atianand MK, Vos MR, Schroder GF, Fitzgerald KA, Wu H, Egelman EH. Unified polymerization mechanism for the assembly of ASC-dependent inflammasomes. Cell. 2014;156:1193-206.

17. Kayagaki N, Stowe IB, Lee BL, O'Rourke K, Anderson K, Warming S, Cuellar T, Haley B, Roose-Girma M, Phung QT, Liu PS, Lill JR, Li H, Wu J, Kummerfeld S, Zhang J, Lee WP, Snipas SJ, Salvesen GS, Morris LX, Fitzgerald L, Zhang Y, Bertram EM, Goodnow CC, Dixit VM. Caspase-11 cleaves gasdermin D for non-canonical inflammasome signalling. Nature. 2015;526:666-71.

18. Shi J, Zhao Y, Wang K, Shi X, Wang Y, Huang H, Zhuang Y, Cai T, Wang F, Shao F. Cleavage of GSDMD by inflammatory caspases determines pyroptotic cell death. Nature. 2015;526:660-5.

19. He WT, Wan H, Hu L, Chen P, Wang X, Huang Z, Yang ZH, Zhong CQ, Han J. Gasdermin $D$ is an executor of pyroptosis and required for interleukin-1 $\beta$ secretion. Cell Res. 2015;25:1285-98

20. Martin-Sanchez F, Diamond C, Zeitler M, Gomez Al, Baroja-Mazo A, Bagnall J, Spiller D, White M, Daniels MJ, Mortellaro A, Penalver M, Paszek P, Steringer JP, Nickel W, Brough D, Pelegrin P. Inflammasome-dependent IL-1 $\beta$ release depends upon membrane permeabilisation. Cell Death Differ. 2016:23:1219-31.

21. Juliana C, Fernandes-Alnemri T, Kang S, Farias A, Qin F, Alnemri ES. Non-transcriptional priming and deubiquitination regulate NLRP3 inflammasome activation. J Biol Chem. 2012;287:36617-22.

22. Py BF, Kim MS, Vakifahmetoglu-Norberg H, Yuan J. Deubiquitination of NLRP3 by BRCC3 critically regulates inflammasome activity. Mol Cell. 2013; 49:331-8

23. Martinon F, Petrilli V, Mayor A, Tardivel A, Tschopp J. Gout-associated uric acid crystals activate the NALP3 inflammasome. Nature. 2006:440:237-41.

24. Mariathasan S, Weiss DS, Newton K, McBride J, O'Rourke K, Roose-Girma M, Lee WP, Weinrauch Y, Monack DM, Dixit VM. Cryopyrin activates the inflammasome in response to toxins and ATP. Nature. 2006;440:228-32.

25. Agostini L, Martinon F, Burns K, McDermott MF, Hawkins PN, Tschopp J. NALP3 forms an IL-1 $\beta$-processing inflammasome with increased activity in Muckle-Wells autoinflammatory disorder. Immunity. 2004;20:319-25.

26. Yajima N, Takahashi M, Morimoto H, Shiba Y, Takahashi Y, Masumoto J, Ise H, Sagara J, Nakayama J, Taniguchi S, Ikeda U. Critical role of bone marrow apoptosis-associated speck-like protein, an inflammasome adaptor molecule, in neointimal formation after vascular injury in mice. Circulation. 2008:117:3079-87.

27. Kawaguchi M, Takahashi M, Hata T, Kashima Y, Usui F, Morimoto H, Izawa A, Takahashi Y, Masumoto J, Koyama J, Hongo M, Noda T, Nakayama J, Sagara J, Taniguchi S, Ikeda U. Inflammasome activation of cardiac fibroblasts is essential for myocardial ischemia/reperfusion injury. Circulation. 2011;123: 594-604.

28. Komada T, Usui F, Shirasuna K, Kawashima A, Kimura H, Karasawa T, Nishimura S, Sagara J, Noda T, Taniguchi S, Muto S, Nagata D, Kusano E, 
Takahashi M. ASC in renal collecting duct epithelial cells contributes to inflammation and injury after unilateral ureteral obstruction. Am J Pathol. 2014;184:1287-98.

29. Komada T, Usui F, Kawashima A, Kimura H, Karasawa T, Inoue Y, Kobayashi M, Mizushina Y, Kasahara T, Taniguchi S, Muto S, Nagata D, Takahashi M. Role of NLRP3 inflammasomes for rhabdomyolysis-induced acute kidney injury. Sci Rep. 2015;5:10901.

30. Munoz-Planillo R, Kuffa P, Martinez-Colon G, Smith BL, Rajendiran TM, Nunez G. $\mathrm{K}^{+}$efflux is the common trigger of NLRP3 inflammasome activation by bacterial toxins and particulate matter. Immunity. 2013;38:1142-53.

31. He Y, Hara H, Nunez G. Mechanism and regulation of NLRP3 inflammasome activation. Trends Biochem Sci. 2016;41:1012-21.

32. Hornung V, Bauernfeind F, Halle A, Samstad EO, Kono H, Rock KL, Fitzgerald KA, Latz E. Silica crystals and aluminum salts activate the NALP3 inflammasome through phagosomal destabilization. Nat Immunol. 2008;9: 847-56

33. Dostert C, Petrilli V, Van Bruggen R, Steele C, Mossman BT, Tschopp J. Innate immune activation through Nalp3 inflammasome sensing of asbestos and silica. Science. 2008;320:674-7.

34. Halle A, Hornung V, Petzold GC, Stewart CR, Monks BG, Reinheckel T, Fitzgerald KA, Latz E, Moore KJ, Golenbock DT. The NALP3 inflammasome is involved in the innate immune response to amyloid- $\beta$. Nat Immunol. 2008;9:857-65.

35. Franklin BS, Bossaller $L$, De Nardo D, Ratter JM, Stutz A, Engels G, Brenker C, Nordhoff M, Mirandola SR, Al-Amoudi A, Mangan MS, Zimmer S, Monks BG, Fricke M, Schmidt RE, Espevik T, Jones B, Jarnicki AG, Hansbro PM, Busto P, Marshak-Rothstein A, Hornemann S, Aguzzi A, Kastenmuller W, Latz E. The adaptor ASC has extracellular and 'prionoid' activities that propagate inflammation. Nat Immunol. 2014;15:727-37.

36. Baroja-Mazo A, Martin-Sanchez F, Gomez Al, Martinez CM, Amores-Iniesta J, Compan V, Barbera-Cremades M, Yague J, Ruiz-Ortiz E, Anton J, Bujan S, Couillin I, Brough D, Arostegui JI, Pelegrin P. The NLRP3 inflammasome is released as a particulate danger signal that amplifies the inflammatory response. Nat Immunol. 2014;15:738-48.

37. Sheedy FJ, Grebe A, Rayner KJ, Kalantari P, Ramkhelawon B, Carpenter SB, Becker CE, Ediriweera HN, Mullick AE, Golenbock DT, Stuart LM, Latz E, Fitzgerald KA, Moore KJ. CD36 coordinates NLRP3 inflammasome activation by facilitating intracellular nucleation of soluble ligands into particulate ligands in sterile inflammation. Nat Immunol. 2013;14:812-20.

38. Kirii $H$, Niwa $T$, Yamada $Y$, Wada $H$, Saito $K$, Iwakura $Y$, Asano M, Moriwaki $H$, Seishima M. Lack of interleukin-1 $\beta$ decreases the severity of atherosclerosis in ApoE-deficient mice. Arterioscler Thromb Vasc Biol. 2003;23:656-60.

39. Chi H, Messas E, Levine RA, Graves DT, Amar S. Interleukin-1 receptor signaling mediates atherosclerosis associated with bacterial exposure and/or a high-fat diet in a murine apolipoprotein E heterozygote model: pharmacotherapeutic implications. Circulation. 2004;110:1678-85.

40. Menu P, Pellegrin M, Aubert JF, Bouzourene K, Tardivel A, Mazzolai L, Tschopp J. Atherosclerosis in ApoE-deficient mice progresses independently of the NLRP3 inflammasome. Cell Death Dis. 2011;2:e137.

41. Pradeu T, Cooper EL. The danger theory: 20 years later. Front Immunol. 2012;3:287.

42. Han S, Lear TB, Jerome JA, Rajbhandari S, Snavely CA, Gulick DL, Gibson KF, Zou C, Chen BB, Mallampalli RK. Lipopolysaccharide primes the NALP3 inflammasome by inhibiting its ubiquitination and degradation mediated by the SCFFBXL2 E3 ligase. J Biol Chem. 2015;290:18124-33.

43. Yan Y, Jiang W, Liu L, Wang X, Ding C, Tian Z, Zhou R. Dopamine controls systemic inflammation through inhibition of NLRP3 inflammasome. Cell. 2015;160:62-73

44. Song H, Liu B, Huai W, Yu Z, Wang W, Zhao J, Han L, Jiang G, Zhang L, Gao C, Zhao W. The E3 ubiquitin ligase TRIM31 attenuates NLRP3 inflammasome activation by promoting proteasomal degradation of NLRP3. Nat Commun. 2016:7:13727.

45. Guo C, Xie S, Chi Z, Zhang J, Liu Y, Zhang L, Zheng M, Zhang X, Xia D, Ke Y, Lu L, Wang D. Bile acids control inflammation and metabolic disorder through inhibition of NLRP3 inflammasome. Immunity. 2016;45:802-16.

46. He Y, Zeng MY, Yang D, Motro B, Nunez G. NEK7 is an essential mediator of NLRP3 activation downstream of potassium efflux. Nature. 2016;530:354-7.

47. Schmid-Burgk JL, Chauhan D, Schmidt T, Ebert TS, Reinhardt J, Endl E, Hornung V. A genome-wide CRISPR (Clustered Regularly Interspaced Short Palindromic Repeats) screen identifies NEK7 as an essential component of NLRP3 inflammasome activation. J Biol Chem. 2016;291:103-9.
48. Shi H, Wang $Y$, Li X, Zhan X, Tang M, Fina M, Su L, Pratt D, Bu CH, Hildebrand S, Lyon S, Scott L, Quan J, Sun Q, Russell J, Arnett S, Jurek P, Chen D, Kravchenko W, Mathison JC, Moresco EM, Monson NL, Ulevitch RJ, Beutler B. NLRP3 activation and mitosis are mutually exclusive events coordinated by NEK7, a new inflammasome component. Nat Immunol. 2016;17:250-8

49. Stehlik C, Dorfleutner A. COPs and POPs: modulators of inflammasome activity. J Immunol. 2007;179:7993-8.

50. de Almeida L, Khare S, Misharin AV, Patel R, Ratsimandresy RA, Wallin MC, Perlman H, Greaves DR, Hoffman HM, Dorfleutner A, Stehlik C. The PYRIN domain-only protein POP1 inhibits inflammasome assembly and ameliorates inflammatory disease. Immunity. 2015;43:264-76.

51. Guiet C, Vito P. Caspase recruitment domain (CARD)-dependent cytoplasmic filaments mediate bcl10-induced NF-kB activation. J Cell Biol. 2000;148: $1131-40$.

52. Humke EW, Shriver SK, Starovasnik MA, Fairbrother WJ, Dixit VM. ICEBERG: a novel inhibitor of interleukin-1 $\beta$ generation. Cell. 2000;103:99-111.

53. Lamkanfi M, Denecker G, Kalai M, D'Hondt K, Meeus A, Declercq W, Saelens X, Vandenabeele $P$. INCA, a novel human caspase recruitment domain protein that inhibits interleukin-1 $\beta$ generation. J Biol Chem. 2004;279:51729-38.

54. Karasawa T, Kawashima A, Usui F, Kimura H, Shirasuna K, Inoue $Y$, Komada T, Kobayashi M, Mizushina Y, Sagara J, Takahashi M. Oligomerized CARD16 promotes caspase-1 assembly and IL-1 $\beta$ processing. FEBS Open Bio. 2015;5:348-56.

55. Yan Y, Jiang W, Spinetti T, Tardivel A, Castillo R, Bourquin C, Guarda G, Tian Z. Tschopp J, Zhou R. Omega-3 fatty acids prevent inflammation and metabolic disorder through inhibition of NLRP3 inflammasome activation. Immunity. 2013;38:1154-63.

56. Zhou R, Yazdi AS, Menu P, Tschopp J. A role for mitochondria in NLRP3 inflammasome activation. Nature. 2011;469:221-5.

57. Razani B, Feng C, Coleman T, Emanuel R, Wen H, Hwang S, Ting JP, Virgin HW, Kastan MB, Semenkovich CF. Autophagy links inflammasomes to atherosclerotic progression. Cell Metab. 2012;15:534-44.

58. Emanuel R, Sergin I, Bhattacharya S, Turner JN, Epelman S, Settembre C, Diwan A, Ballabio A, Razani B. Induction of lysosomal biogenesis in atherosclerotic macrophages can rescue lipid-induced lysosomal dysfunction and downstream sequelae. Arterioscler Thromb Vasc Biol. 2014; 34:1942-52.

59. Shi CS, Shenderov K, Huang NN, Kabat J, Abu-Asab M, Fitzgerald KA, Sher A, Kehrl JH. Activation of autophagy by inflammatory signals limits IL-1 $\beta$ production by targeting ubiquitinated inflammasomes for destruction. Nat Immunol. 2012;13:255-63.

\section{Submit your next manuscript to BioMed Central and we will help you at every step:}

- We accept pre-submission inquiries

- Our selector tool helps you to find the most relevant journal

- We provide round the clock customer support

- Convenient online submission

- Thorough peer review

- Inclusion in PubMed and all major indexing services

- Maximum visibility for your research

Submit your manuscript at www.biomedcentral.com/submit
) Biomed Central 